\title{
Marca Perú: ¿una nación en construcción?
}

\author{
Elder Cuevas \\ (Universidad de Lima, Perú)
}

Recibido: $25 / 1 / 2016$

Aprobado: 3/3/2016

Resumen: En el marco de esta última década y de la embriaguez vivida por el redescubrimiento o -seudorrevaloración- del Perú a partir de la gastronomía, el turismo y el crecimiento económico, esta investigación emplea la teoría semiopsicoanalítica y poscolonialista para explicar cuál es el panorama social del Perú sobre el concepto de nación, su reencuentro con una identidad inexistente y la construcción de una idea de país a partir de la campaña publicitaria Marca Perú. Así, Marca Perú, lejos de unir a los peruanos y convocarlos en el tan afamado "crisol de razas", se convierte en la resemantización del viejo discurso colonial, en donde todavía se anhela una república sin indios. Por eso -esta vez- los 'indios' "vienen" importados desde Nebraska, son blancos y hablan inglés, tal como lo propone la campaña publicitaria.

Palabras clave: nation-branding / interculturalidad / Perú / poscolonialismo / nación

\section{Peru Brand: a Nation under Construction?}

Summary: During the last decade Peru has experienced a euphoric rediscovery -pseudo revaluation as a country- due to its booming gastronomy, tourism and economic growth. In this context, the present research uses semio-psychoanalytic and postcolonial theories to explain Peru's social outlook regarding the concept of nation, its reunion with a non-existent identity and the construction of the idea of nation based on the marketing campaign titled the Peru Brand. Thus, Peru Brand, far from uniting all Peruvians and bring them together into the wellknown "melting pot", becomes the resemantization of the old colonial discourse longing for a republic without natives. Therefore, in the Peru Brand advertising discourse, the "primitive natives" are white people brought from Nebraska and speak English.

Keywords: nation-branding / pluricultural / Peru / postcolonialism / nation 
Los gobiernos son simples agentes de negocios del capital internacional: esta tesis hasta hace poco escandalosa de Marx es hoy en día la evidencia sobre la cual se ponen de acuerdo "liberales" $y$ "socialistas".

La identificación absoluta de la política con la gestión del capital ya no es un secreto vergonzoso que enmascararían las "formas" de la democracia, es la verdad declarada con que se legitiman nuestros gobiernos.

Jacques Rancière El desacuerdo

\section{Introducción}

$\mathrm{M}$ ucha agua, o para nuestro caso "mucha tinta", ha corrido debajo del puente para tratar de explicar lo que acontece en el Perú. La "sombra" colonial se erige como presencia ubicua en la que todos los procesos sociales se ven envueltos. Y es que ante la dialéctica de los sujetos que no se reconocen, pero que habitan un cuerpo dislocado, las interacciones cotidianas se entraman en una seguidilla de encuentros y desencuentros, que son la muestra de un país en el que coexisten mundos diversos que se mezclan y se ignoran.

Aunque pueda resultar tentador dar un diagnóstico a la postre de un pasado casi fosilizado por sus prácticas coloniales que aún perduran en nuestra sociedad -si no veamos cómo, hoy en día, las empleadas del hogar caminan unos pasos atrás de la "señora de la casa" en el supermercado, o incluso se refieren a ellas como "niñas" denotando claramente el paternalismo-, lo cierto es que los diversos procesos históricos que vienen desde la invasión española, la constitución de la República y la gran migración del siglo XX, trajeron consigo una mutación en el desarrollo del colonialismo. El Perú, especialmente Lima -la ciudad de los Reyes, canónica, señorial- ha dejado su hálito virreinal para también ser la ciudad de los Reyes, de los Chávez y de los Quispe ${ }^{1}$.

Para autores como Portocarrero (2010, 2013, 2014) o Arellano (2007, 2010) la "mácula" indígena no es más un motivo de remembranza inmediata a un pasado servil, sino - por el contrario-es la matriz en la que se inscribe un nuevo país lleno de migrantes que miran hacia el futuro con esperanza, pero que al mismo tiempo mantienen una fuerte conexión con sus antepasados.

Los surfers, los cajoneros, los cocineros, las actrices y hasta los bufones se concentran en un nuevo escenario, donde no pareciera importar el color de la piel, sino únicamente su sentimiento de nuevos sujetos sociales en un mundo urbano que se mueve al ritmo del mito del progreso. Justamente, es en este escenario donde la "sombra" colonial se va disipando, aunque de manera lenta y desigual.

1 Este juego de palabras se inspira en el libro homólogo de Rolando Arellano y David Burgos (2010). 
'El Perú avanza' parece ser el apotegma que guía todas las narrativas que se construyen alrededor de lo nacional; y es que, de un tiempo a esta parte, una extraña mezcla entre el optimismo, la identidad social, la autoestima, la libertad económica y el emprendedurismo, dieron como resultado la idea de un país cada vez más unido, que revalora lo propio, en donde la gastronomía ha tumbado los muros que separaban a los dos Perú de Basadre. Pareciera que todo esto, finalmente, nos llevará a la utopía de la comunidad imaginada de Anderson (1983), donde todos nos encontraríamos como paresiguales, para así, finalmente, imaginarnos como una unidad.

Sin duda estamos ante un nuevo Perú, pero que más allá del crecimiento económico, el desarrollo, el progreso que se siente en algunas economías, todavía persisten fallas estructurales que impiden esclarecer cuál es la situación actual que nos embarga. ¿Es posible que los peruanos, a pesar de todas las taras que mantienen, puedan imaginarse como 'una sola nación'? Al igual que la propuesta de Chatterjee (2008) sobre la imposibilidad de imaginar a la nación poscolonial como una sola, del mismo modo en el Perú es una tarea espinosa el pensar (o imaginar) a todos los peruanos como sujetos con igualdad de derechos, posibilidades y condiciones de poder ejercer su ciudadanía. Y es que al convivir en una modernidad fragmentada -que aún se amamanta de la praxis colonial- la dificultad radica en poder entendernos como sujetos, con los mismos derechos y deberes.

En efecto, lo dicho no aclara absolutamente nada; solamente repite lo debatido por diversos autores. Sin embargo, el párrafo anterior nos deja preguntas abiertas: ¿es posible curar la herida colonial? ¿Es posible dejar atrás estas fallas estructurales para poder pensarnos como un todo? Y si, aún la mácula colonial nos parece perseguir y mediar nuestras interacciones, entonces, ¿en qué sentido disfrazamos las viejas inequidades económicas y culturales? En pocas palabras, ¿en qué hemos cambiado?

Claramente nos daremos cuenta de que los cambios, expresados a modo de síntomas, se erigen en lo más visible del espacio de lo social. El Perú pasó de tener una economía de crecimiento discreto a dispararse en un $10 \%$, haciendo de esto la 'envidia' de otras regiones; Machu Picchu pasó a ser una de las nuevas maravillas del mundo, $\mathrm{y}$-finalmente- una cocina subalterna devino en la cuisine más valorada alrededor del globo. Sin embargo, debemos ser críticos y observar que estos hechos no responden a un cúmulo de situaciones fortuitas, que hicieron de la sumatoria la actualidad del país.

Muy por el contrario de lo que se piensa, nos daremos cuenta -a lo largo de estas líneas- que los síntomas observados no son más que respuestas a un largo proyecto, que busca virar el foco estadista a la construcción de nación para darle un aire más independiente 
y reivindicador, y que hacia estos años ya ha empezado a dar sus frutos. Si tomamos la frase popular 'sembrar para cosechar', nos daremos cuenta de que la primera fase ya fue ejecutada; se ha sembrado un cambio discursivo - de lo 'patriótico' a lo 'nacional'- y es ahora que esa siembra ha empezado a ser cosechada en la música, la gastronomía, la moda, pero principalmente en la concepción de nación, a partir del registro publicitario que escenifica la campaña 'Marca Perú' ${ }^{\prime 2}$.

Atrás parece quedar el 'discurso patriótico', que comprendía el heroísmo de la bandera o el romanticismo utópico del Inca inmaculado, para quedarnos con un 'discurso nacional' que no se enorgullece de un pasado fosilizado; sino que, por el contrario, lo hace desde lo fáctico, lo visible, desde una imagen 'real' dada por la economía, el turismo, la gastronomía y la frase del " ¡Sí se puede!". Por oposición, nos daremos cuenta de que este primer discurso pierde actualidad porque apela a lo onírico, a lo inmaterial, a la fantasía; en vez de ser pensado desde y por los habitantes, se hace desde el Estado y -por tanto- promulgado por una ley cuya finalidad pretende una perpetuación y permanencia; en otras palabras, ser el "discurso oficial". De modo que no es gratuito que, en todo este cambio de discurso, el inca y la bandera fueran reemplazados por el ceviche y la papa rellena.

Por eso, el discurso de la bandera de San Martín, al igual que la visión de Manco Cápac como alguien "sabio" (Méndez, 1995) -mientras ocurra en el pasado y sea abstracto-, es la encarnación de lo onírico e inmaterial que por muchos años ha comandado el modo en que se ha imaginado el discurso patriótico. Siempre bajo los lemas ‘Perú, donde la historia vive'; 'Perú, país de los Inkas'; 'Perú, vive la leyenda'; 'Perú, imperio de tesoros escondidos'; la isotopía /atemporal/ y /mística/ gobiernan estas narrativas. Pero que al fin y al cabo nos devela que el punto de partida enuncivo ${ }^{3}$ lo hace el Estado desde su visión romántica, pero que hoy en día, al representarse de ese modo, nos genera una suspicacia; más aún en un tiempo en que la crisis de autoridad es visible en la sociedad peruana. Con leyes que no son acatadas

2 Esta síntesis parte de la lectura de los trabajos realizados por Bruno Seminario, Cynthia Sanborn y Nikolai Alva (2013), para entender (y comprender) de dónde proviene el tan afamado crecimiento ejemplar. Del mismo modo, la conversión del proyecto turístico es observado por Norma Fuller (2009) y María Eugenia Ulfe (2011); finalmente, la cocina y su relación con la nación a partir de Alexis Patiño-Patroni (2013) y Pedro Pablo Ccopa (2014).

3 A fin de alinear al lector en la jerga semiótica, hacemos la diferencia entre lo 'enuncivo' y lo 'enunciativo'. El primero -tal como se escribe en la oración- hace referencia a lo explícito, a la información transmitida; mientras que lo segundo refiere al proceso que subyace desde una instancia del enunciado, ya sea espacial, temporal o actorial. 
o son abiertamente resistidas, el discurso patriótico, como un todo inmaculado, queda desactualizado.

Así, al intentar replicar la narrativa del 'discurso patriótico', inmediatamente se inscribe el escenario de la corrupción de los de arriba y la violencia de los de abajo; -sumado a la impunidad con la que actúan las autoridades, además del afianzado sentido común sobre el orden inaugural que tiene la autoridad para incumplir las leyesdonde no hay razón para el compromiso por parte de los ciudadanos. Por eso en nuestra sociedad, inmersa en un estado de excepción (Agamben, 2005), coexisten tras "la autoridad, las figuras del representante y del patrón, $\mathrm{y}$ tras los representados, las figuras del ciudadano y del siervo" (Portocarrero, 2010, p. 13). Así, la lógica que conlleva la desconfianza junto con el fantasma colonialista nos dan un escenario ríspido, donde la ley desajusta a la autoridad, la propone como obsoleta, pero, principalmente, como corrupta.

Es, justamente, en ese momento inbetween que la normativa del 'discurso patriótico' viene cargado de un tufillo sospechoso y hasta amenazador. La visión habitual del Inca en la montaña o atrapado en el tiempo, como una visión romántica y onírica que ha trabajado el Estado, se vio desgastada al punto de convertirse en una mirada "solo para turistas". Alejado de la nación, la representación de lo patriótico devino arcaico y solemne.

Por el contrario, el 'discurso nacional' se presenta como resultado de determinaciones causales, incluso paradójicas. Fruto de la creatividad propia de los sujetos (y no de las autoridades) el 'discurso nacional' se presenta como consecuencia de una inscripción de los valores vida, de la praxis y no de una institucionalidad, de un 'acontecimiento' y no de una premeditación, que opone diferencias, que es materia comunal, que se esparce y se engloba, una mixtura de eventos. Así, el símbolo nacional se destaca en la fiesta, en el entretimiento, en lo espontáneo, lo corriente, lo sencillo, en la "libertad" de ser ciudadanos.

Si lo consideramos en los ámbitos de la ceremonia y de la celebración, el "símbolo patrio" pertenece a la ceremonia [de la bandera, de los incas, del ritual, del país que nos espera], mientras que el "símbolo nacional" a la celebración [de ser libres, independientes, de construir una nueva peruanidad]. (López Maguiña, 2007, p. 353)

En pocas palabras se nos narra en el 'discurso patriótico' de un 'allá-entonces', mientras que en el 'discurso nacional' se nos narra desde un 'aquí-ahora'.

Frente a esta polarización enunciativa entre 'Estado' -que mira al Perú, en un tiempo desembragado- y la 'nación' -que la embraga hacia un aquí/ ahora-, la publicidad ha sabido encontrar en la desconfianza y la fosilización de los símbolos tradicionales, la nueva narrativa que dibuja el 'discurso nacional'. De allí que no sean gratuitos los lemas celebratorios de las campañas publicitarias que nos avisan del "gran cambio" nacional. Desde Inca Kola, y 
su celebración de la creatividad, pasando por Plaza Vea, que se enorgullece de ser peruano, hasta llegar al cuy mágico del BCP, que da la bienvenida al éxito, en todos los casos nos daremos cuenta de que el orgullo no proviene de su relación con el pasado, sino de la capacidad de poder abrirse campo en este momento; no por la herencia milenaria ni por una esencialidad, sino por la capacidad de enfrentarse a la adversidad. Sin embargo, démonos cuenta de que aquello que comanda estas estrategias no es una voluntad nacionalista, sino -por el contrario- es una pretensión comercial que a través del lovermark vincula una sensación a los productos de esta nueva narrativa.

Debemos precisar que lo sostenido no se ampara en una simple intuición de las agencias publicitarias. Muy por el contrario, es a partir del estudio de mercado que toda esta narrativa empieza a cobrar forma, y así el mercado y la nación inician una alineación que conjuga sus visiones sobre el Perú.

Incluso, si seguimos el trabajo de Rolando Arellano (2007, 2010), nos daremos cuenta de que toda esta narrativa del discurso 'nacional' empieza a ser delimitada por lo que él denomina 'los nuevos peruanos'. Aquellos que dan un nuevo semblante a un país que intenta cambiar su mentalidad, siendo más op- timistas sobre el futuro y con una autoestima nacional; la conformación de lo peruano se abre paso, aunque aún conserve en su estructura la falta de tolerancia y escaso compromiso político. Es a partir de este distanciamiento de lo político $-y$ por transferencia del 'discurso patriótico'- que las directrices del marketing parecieran encarnar una nueva suerte de poder pastoral que nos llevó del confesionario al restaurante ${ }^{4}$. En pocas palabras, "el nuevo peruano es más divertido, sociable y emprendedor, cree en su futuro y se siente más dueño de él, pero también tiene desconfianza, miedo e inseguridad social" (Arellano, 2010, p. 183).

Hay que remarcar la entrada que propone el marketing para hablarnos de los nuevos peruanos. Es optimista, se nos dice, porque ya no ve en la migración una meta de progreso; $\mathrm{y}$ aunque puede ser desconfiado del crecimiento económico, al ver por las calles la fiebre del concreto, deposita su confianza en que las cosas 'deben' estar yendo bien. Y justamente, porque las cosas al parecer se han enderezado, siente que hay motivos para enorgullecerse. Eso, además de apelar a su creatividad, ingenio, espíritu de colaboración y solidaridad, nos lleva a la idea de que 'el peruano no se muere de hambre, sale adelante'.

4 Si seguimos a Foucault (1999), estaríamos en un momento en que el poder del pastor guía a la manada hacia el sendero de la ideología: ‘Sí se puede!'. Sin embargo, debemos ser cuidadosos con este concepto, pues su implicancia es mayor a la de un relato optimista; por eso volveremos sobre esto más adelante. 
De ese modo, con la creatividad y el ingenio como el denominador de la identidad nacional, la sensación de haber conseguido una nación de todas las sangres pareciera estar a la vuelta de la esquina. La publicidad y la televisión, los dos bastiones de la burguesía tradicional limeña, ahora nos presentan grandes campañas protagonizadas por cantantes de cumbia (Tongo, Deyvis Orozco), e incluso toman el prime-time para narrar con miniseries las historias de sus vidas; que no es más que un duro y largo proceso de lucha ante una sociedad que los miraba con el rabillo del ojo.

Así, el emprendimiento es el sostén del orgullo reinante, pues al situarse en una posición adversa, donde las leyes están hechas para favorecer a los ricos y desangrar a los pobres, el migrante tuvo que abrirse campo en un país que en vez de protegerlo laboralmente lo dejó al abandono. Ante esta adversidad, el emprendedor se abrió paso arriesgándose con el negocio propio, sin jefes que lo regulen, sin reglas a las cuales ceñirse, todo en función de lograr el peruvian way of life.

Evidentemente, esto no podría darse en un modelo que no sea el liberal, que le ofrezca la garantía de que su esfuerzo no se verá afectado. Entre el liberalismo económico, la apertura de consumo y el pragmatismo político, el 'nuevo peruano' entiende que el enfoque del país tiene que ser global y de inserción mundial. Sin fidelidades políticas firmes o permanentes, votará por aquel candidato que se acomode a la coyuntura. Finalmente, todo termina por resumirse en la apertura de consumo y el disfrute como los pilares que fundamentan esta nueva peruanidad.

De este diagnóstico es que se nutre el 'discurso nacional', y, por ende, nos muestra en cada una de las publicidades a un peruano que se adscribe a cada una de estas directrices. De ese modo, no es gratuito el tono celebratorio y las situaciones que encontramos en cualquier representación que haga referencia al escenario actual del Perú. Porque el presente y el futuro se leen en clave de construir un país para todos, sin intermediarios, por los peruanos para los peruanos, desde las costumbres, desde los encuentros (y desencuentros), desde aquellas cosas que "sacan la cara" por los peruanos, por la Inca Kola y por Mistura, desde el mercado, al fin y al cabo. Por eso, cuando examinamos el 'discurso nacional', nos damos cuenta de que el Estado devino empresa, y el ciudadano devino cliente.

\section{Un peruano no nace, un peruano se hace}

Incluso, si vamos un poco más allá, Arellano y Burgos (2010) hacen un diagnóstico de cómo será el futuro peruano; en pocas palabras: un 'mejor consumidor'. Más educado (y adecuado), exigente en cuanto a sus derechos y satisfacciones de necesidades. Ya no es al que se le daba 'gato por liebre'. Un consumidor más formado, 
capaz de premiar a las empresas que lo satisfacen adecuadamente, lo que definitivamente conlleva una enorme oportunidad de desarrollo para los negocios que sepan escuchar a sus consumidores y, a partir de esto, puedan darle lo que piden de una manera más eficiente que su competencia, tal como lo señala la disciplina del marketing.

Esto último es lo que comanda el norte de la nueva peruanidad: el marketing. Entonces, la pregunta es inmediata: ¿por qué emplear el marketing para narrar la nación? Como ya lo habíamos tratado líneas atrás, lo que el recuerdo nos dicta sobre los últimos años, más específicamente entre el paso de los gobernantes de la década del ochenta, noventa y comienzos del nuevo milenio, es que se preocuparon por engrosar las arcas fiscales para luego vaciarlas en su propio beneficio. Esto -en el imaginario de los peruanos- se pensó como un giro en torno a que los gobernantes únicamente dedicaron sus esfuerzos a hacerse más ricos, dejando de lado la tan afamada inversión.

Así, el nacionalismo, desprovisto de los márgenes estatales, se trasladó al consumo. Pero para Arellano este nacionalismo es reactivo, pues el sentimiento no habría nacido solo por el amor que se pudiera tener a lo perua- no, sino, más bien, como reacción de defensa ante diversos acontecimientos, como los 'maltratos' que, desde la perspectiva de la opinión pública -muchas veces alimentada por los medios masivos de comunicación-, el consumidor peruano habría sufrido por parte de algunas compañías extranjeras.

De allí que este sentimiento nacional habría nacido también como respuesta a la crisis de valores vivida en el país a finales de la década de 1990. Si antes, al preguntar por personajes admirados, surgía una lista interminable de nombres, hoy, al hacer la misma pregunta, literalmente la gente se queda muda. Ante esta falta de referentes humanos de los cuales enorgullecerse, pareciera que los peruanos encontraron en los productos como la comida o la música, un motivo para creer nuevamente en el país, porque estos productos no vacían las arcas fiscales, no se cambian de partido político ni renuncian a la presidencia ni a su nacionalidad vía fax.

Por eso, el Estado ha retirado su presencia $^{5}$ para cederle el paso al marketing, pues, al fin y al cabo, si el Estado ha bajado -parafraseando la jerga política- su índice de popularidad, "el marketing [por el contrario, se plantea como algo que] puede hacer más felices a los individuos, más

5 Al hablar de presencia lo hacemos en los terrenos del campo semiótico donde se organiza en torno al sentido de origen: está presente aquello que está ahí, in vivo, hic et nunc, en una constelación deíctica, captable por extensión. De tal modo que la presencia en cuanto tal es observable, sensible para la vista esencialmente pero también para el oído y para 
prósperas las empresas, más eficientes a las instituciones, más ricos a los países" (Arellano, 2007, p. 11). Sin embargo, no debemos ser ingenuos y pensar que el marketing se abre paso entre los ciudadanos como una disciplina inmaculada, exenta de cualquier discrepancia. No es un secreto que el marketing también es visto como una herramienta pérfida, con una única voluntad de engañar a sus usuarios. Entonces la pregunta se hace evidente. Si el Estado ya no es garante de nada, y el marketing tampoco es del absoluto agrado, ¿por qué encargarle la narración de la nación a esta disciplina?

$\mathrm{Si}$ el Estado parece la suegra que nadie quiere tener, Arellano (2007, 2012, 2013) nos recuerda que emplear el marketing no es nada más que usar el nivel adecuado de maquillaje para mejorar la imagen y atraer al cliente sin alejarse 'demasiado' de la realidad prometida. Y es que, en efecto, esa es la meta del Estado, hacer con el marketing que esa suegra sea, al menos, más presentable. Lo sabemos: el maquillaje no cambia nada, ipero cómo ayuda!

Ahora bien, tengamos en cuenta que estamos hablando de una discipli- na inscrita 'en' el mercado, y por eso el prefijo del significante no oculta su origen (market). Si ya desde los lineamientos del 'nuevo peruano' se afirma que el mercado es el garante de la estabilidad, no es gratuito que el marketing se haga cargo de la imagen del Estado. Sin embargo, allí es donde radica lo peliagudo de extender la narrativa de una nación al marketing, porque implica sustancialmente la 'satisfacción de las necesidades' de los consumidores.

Así como en el epígrafe de este escrito, Rancière reflexiona sobre la falta de 'pathos de la indignación' al saber que el Estado y la empresa no se avergüenzan más de su affair, la lógica empresarial se ha enquistado en una política que ha hecho metástasis. Por eso, ahora la función de la empresa (Estado) no es solo crear clientes (nación), sino también fidelizarlos. En otras palabras, el negocio que se trabaja aquí es el de un Estado que piensa su estructura como empresa, y donde lejos de pensar en ciudadanos piensa en clientes; vale decir, el target a los que el maquillaje debe llegar. De ese modo, el Estado no quiere que la gente compre o se sienta más feliz, sino, por

los sentidos íntimos, el olfato, el gusto y el tacto. Pero también puede ser 'presencia nopresente', como la "presencia de un país o de una actriz en el escenario", que consiste en adueñarse del espíritu e imponer fuertemente la atención. Esos tipos de superpresencias se imponen peligrosamente según el modo del simulacro y de la seducción (Parret, 2008, p. 11). Aquí, justamente, la presencia del Estado ha pasado de estar presente en toda enunciación publicitaria y social a 'no-presente', de modo que si bien no ha desaparecido, aún ronda por allí, pero la imagen que nos deja es la de estar allí no como un ente rector sino como un supervisor. 
el contrario, busca disciplinarlos a un nuevo tipo de ciudadanía, a partir de un mecanismo del poder (el mercado).

Que el Estado emplee el marketing como una tecnología del poder es, justamente, porque hoy en día esta disciplina parece conocernos mejor que nuestro psicoanalista. Es la lógica primordial que se erige sobre el conocer y comprender al consumidor para que el producto que se le ofrezca se le adapte $\tan$ bien que se venda solo, pero que en clave estatal podríamos leerla como vigilar y castigar ${ }^{6}$. Si en el 'discurso patriótico' la figura del Estado -como un ente absoluto que dejaba ver su poder en la plaza central- está venida a menos, en el 'discurso nacional' la punición ahora viene en clave de biodisciplina. De allí que en toda la campaña de la 'Marca Perú' el dictado de los derechos de esta nueva peruanidad no se dé en el orden de justicia, redistribución o reconocimiento, sino en clave de comer, bailar y surfear; en pocas palabras, 'performar' la peruanidad. Por eso nos apoyamos en Simone de Beauvoir para decir que 'un peruano no nace, un peruano se hace' (desde el marketing).

\section{Hoy molestias, mañana sonrisas: una nación en construcción}

En efecto, nos encontramos en plena construcción de la nación. Dijimos que la peruanidad no se hereda sino que se construye, y los argumentos expuestos enmarcan el marketing como una tecnología del poder que no se ocupa de la venta de un producto sino de la construcción de una marca7. En efecto, una marca que 'marca' un vínculo emocional, y que -al margen de ser solo una campaña publicitaria- el marketing utiliza el nation branding como una estrategia a largo plazo. Y es que al ser la nación un organismo vivo y no

6 Si tomamos prestada la tesis desarrollada por Foucault (2014) nos daremos cuenta de que la vigilancia viene ligada al consumo del discurso, y de todas sus variables físicas (mercancías). Por eso, al igual que el panóptico, el marketing maximiza su observación desde un lugar que no puede ser visto, y que, por el contrario, se trata de presentar como algo ausente. Sin embargo, cuando alguien excede el discurso (de la peruanidad) el castigo se hace inminente; esta vez no con una cárcel sino con la acusación de 'no-ser-peruano', y devenir paria. Si no recordemos el comentario de Iván Thays sobre lo indigesta que es la comida peruana. Tanto los medios de comunicación como la opinión pública se volcaron contra él. Calificativos como antiperuano, resentido o incluso terrorista, dictaminaron la condena a un hombre cuyo único 'delito' fue opinar en contra del discurso dominante. Por eso, el subtítulo del libro de Foucault nos es de suma importancia aquí para hacernos una pregunta: ¿con la llegada del marketing ha nacido una (nueva) prisión?

7 En términos de Simon Anholt (2007), es fundamental diferenciar brand de branding. El primero es un producto, servicio u organización, que considera en combinación con su nombre, su identidad y su reputación. El segundo es un proceso de diseño, planeamiento 
una mercancía, debemos entender la tecnología del poder más allá de ser el guion del Estado neoliberal; la verdadera naturaleza de su acción es que ha devenido forma de gobierno.

Sin embargo, nada se puede hacer sin la fuerza, o como Toni Puig (2008) llama la 'voluntad' y la 'actitud' de los involucrados. En pocas palabras, el marketing emplea el nation branding como el catalizador de un modelo corporativo, donde lo más importante es que prevalezca un 'buen clima laboral'. Así, la labor gubernamental no radica en la implementación de decretos o leyes sino en diseñar y rediseñar la configuración de la imaginación y la acción comprometida que involucre a sus habitantes. Por eso, el tenor con el que se erige la 'Marca Perú' siempre está en clave de construcción; en otras palabras, 'siempre hay algo por hacer'; siempre hay algo que performar. En síntesis, se performa la nación porque hay una falencia, porque hay un valor por construir, un 'algo' intangible que sirva como punto de capitón ${ }^{8}$, como una barrera que impida una vorágine de significantes a la deriva. Algo que pueda ser identificable como 'el significante' que sostenga a la 'Marca Perú'. De allí que el peso de esta búsqueda no recaiga en los partidos gubernamenta- les sino en 'líderes creativos', gente que emerge desde el propio 'clima laboral' y cuyo horizonte siempre está en búsqueda de un nacionalismo más benévolo, inclusivo y flexible.

No obstante, esta fórmula idílica no es más que una visión pacífica y humanista que sostiene los conflictos, y que -por tanto- vacía los contenidos para llenarlos de 'diversidad' a cualquier costo. La promesa parece estar dada: hoy molestias -porque aún no está afianzado el discurso-, mañana sonrisas -cuando finalmente todo esté despolitizado-. Aquí radica la raíz de nuestra discrepancia con este modelo, pues al dejar el país en manos de la 'Marca Perú' -que, al fin y al cabo, es un modelo de percepción que no posee fundamentos sino una corazonada- el semblante colonialista contraataca. De ese modo, como rezaba un viejo eslogan publicitario, 'los años pasan pero la calidad queda', nosotros podemos afirmar que 'los años pasan pero la colonialidad queda'.

\section{Resabios coloniales en una aparente modernidad}

Ahora bien, observemos la figura 1 (véase la p. 106). Es la portada del se-

y comunicación del nombre y de la identidad, en orden de construir o manejar una reputación. Porque no solo se trata de clichés, sino de sostener toda una 'identidad competitiva' alrededor de lo promocionado.

8 En la jerga psicoanalítica lacaniana se entiende al punto de capitón como un punto de abrochamiento que contiene el deslizamiento de los significantes y fija un significado determinado. 
gundo número de Industria Peruana, de noviembre de 1931, editada por la Sociedad Nacional de Industrias. ¿Qué podemos observar allí y cómo se relaciona con nuestro objeto de estudio? ¿Existe relación entre la portada de una revista de la década del treinta con un documental/spot publicitario realizado ochenta años después?

Al parecer no; sin embargo, observemos. En principio, esta imagen sintetiza el espíritu del tiempo en el que aparece. Pensemos que tras la bonanza dejada por los recursos guaneros

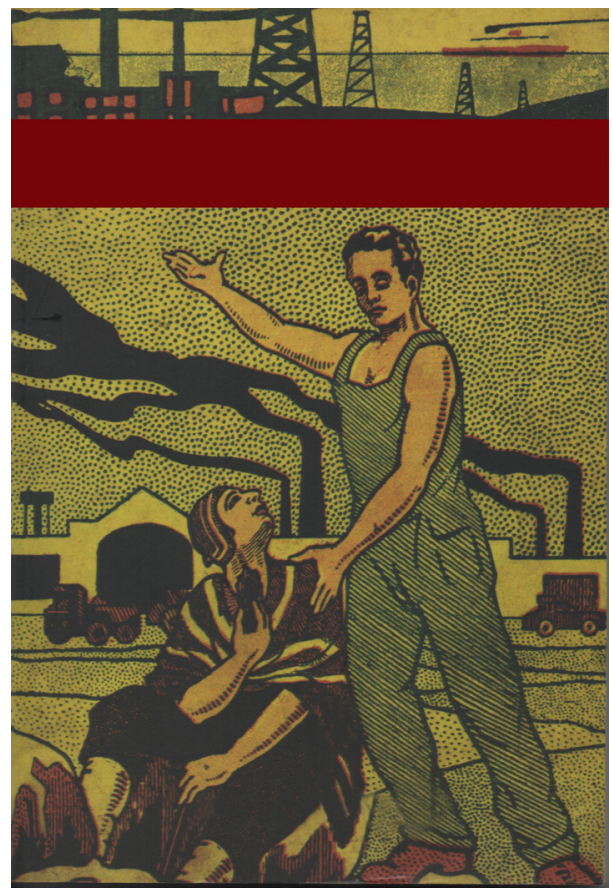

Figura 1. Portada de la segunda edición de la revista Industria Peruana, de noviembre de 1931, periódicamente renovada por la Sociedad Nacional de Industrias. Dibujo de A. G. Rossell. Ilustración tomada de la portada del libro The Allure of Labor (2011), de Paulo Drinot. hacia finales de la década de 1920 y comienzos de los años treinta, el camino hacia la modernidad tenía nombre propio y albergaba un hálito esperanzador: la industrialización.

Pero esta propuesta no venía sola, sino con un suplemento que 'complejizaba' el discurso. Prueba de ello es la ilustración que observamos como portada de la revista. Démonos cuenta cómo la polarización es inmediata. Por un lado está un trabajador vestido con overol y con botas, de pie, con una mano que guía el camino esperanzador; el trabajo vía la industrialización. Por otro lado, al costado se presenta al andino, que -por oposición- aparece sentado, vestido de poncho $y$ chullo; además de aferrar un puñado de hojas de coca a su pecho. Esta imagen inmediatamente contrapone dos posturas antagónicas: la espera (que nos recuerda a la vieja homologación de Raimondi sobre el 'Perú como un mendigo sentado en un banco de oro') y la acción (por parte del trabajador, o que hoy en día podríamos darle el nombre de emprendedor).

Sin embargo, no solo queda allí el antagonismo. El trabajador, que es representado con el fenotipo blanco/ mestizo, posa su mano izquierda en el hombro del andino y con la derecha atrae su atención hacia el fondo: un fondo compuesto por fábricas con chimeneas humeantes en signo de producción, custodiados en la puerta por un tractor y un camión. Del mismo modo, en la parte superior de la fotografía vemos cómo la industria 
se focaliza una vez en fábricas, torres de perforación petrolera, caña de azúcar, y en el fondo más lejano la clave de todo: el barco que nos permite seguir hablando de la industrialización, aunque también nos deja suelta la idea que el progreso viene desde el mar. En otras palabras, el progreso viene en un barco, porque solo así se romperá el vínculo con el pasado indígena. Léase, una homogeneización de migrantes que construyen la sociedad. Junto con lo propuesto, una pista más nos devela el hálito con el que esta portada fue diagramada. En la portada original, a la que no tuvimos acceso de reproducción, se escribe "Proteger a la industria es contribuir a la sociedad".

Evidentemente, en aquel tiempo, el 'deber patrio' radicaba en la protección de la sociedad. Dicho de otra forma, el 'deber patrio' se narraba casi a modo de wéstern, donde la génesis de la civilización debía ser defendida de los indígenas que solo buscaban "obstruir" el progreso. De allí que en la ilustración se haga hincapié en la relación del hombre con la naturaleza, del hombre y su vínculo con la atemporalidad. Por eso los pies del indígena aparecen enterrados, introducidos en la tierra en donde se construye como la unidad /hombre-naturaleza/, mientras que el trabajador, por el contrario, aparece con los pies por encima del terreno, con unas botas que le impiden el contacto (o la conexión) con ese lugar.

Por eso debemos entender que la entrada a la modernidad a través de la industrialización, más que un proyecto económico, era un proyecto de aspiración social. Las élites entendieron la industrialización en clave de la encarnación de un proyecto para 'mejorar la raza'. La fotografía expresa, al mejor estilo propagandístico de los fascistas europeos o del régimen soviético, la imagen de la identificación del progreso nacional con 'la creación de un nuevo hombre'.

La imagen del indio y del trabajador, en contraposición del pasado/presente y el futuro, articula la creencia de las élites en razón del poder transformativo de la industrialización, no localizándola en la esfera económica sino en la racial y cultural.

En síntesis, la imagen congrega el poder -mágico- de la industria para transformar el pasado indígena de barbarie en mestizos -blancos- civilizados. Por eso, la imagen enfatiza la naturaleza y condiciones de ser ciudadano: en pocas palabras, no-indígena $y$, por tanto, blanco/mestizos. De este modo, bajo este discurso, la imagen, estaría solamente (bien) constituida cuando la industrialización transformara a los indígenas en trabajadores.

Años después -como nos muestra la figura 2 (véase la p. 108)- nos encontramos con este trabajador; sin embargo, el matiz en teoría ha cambiado. Veamos que ya no es el mismo joven trabajador que señalaba el camino, sino ahora es un hombre barbudo, mayor, subido de peso, al que le gusta la papa. $Y$ en el que ciertamente podemos ver el 


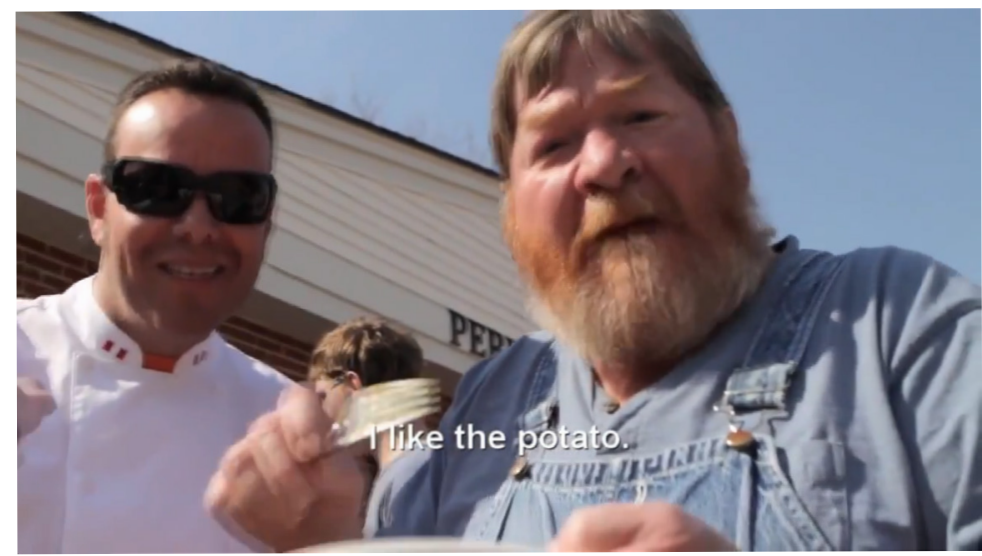

Figura 2. Me gusta la papa. Fragmento del documental/spot publicitario Marca Perú. Fotograma extraído del mencionado documental (video oficial, 2011).

embate del tiempo, o de una industrialización fallida que en vez de convertir bárbaros en civilizados, o indígenas en trabajadores, lo que hizo fue condenarlos a la desidia, a la indiferencia, a la inanidad, o simplemente a la sempiterna conformación del 'Otro'.

\section{Del indio al campesino: mapear la ideología, mapear lo imaginario}

Ahora bien, la pregunta con la que se inauguran todos los debates sobre los tres spots de la 'Marca Perú' es: ¿existe relación entre la imagen y su referente? Al hacernos esta interrogante nos preguntamos si no son acaso las miserias y los problemas del Perú parte de su realidad. ¿Acaso estos spots se crean con una mirada perversa que busca, exclusivamente, ocluir los antagonismos sociales?
$\mathrm{Y}$ es que, aunque son spots publicitarios, el tenor con el que fueron presentados en un principio es el del documental. De modo que la frontera ficcional de la campaña publicitaria se fundiera en la verosimilitud plena que propone el documental. Por eso, en un primer momento se presenta al espectador como prueba fehaciente de un registro inmaculado. Se nos plantea como si estos personajes, con una sola cámara al hombro, intervinieran dos ciudades con nombres iguales o relacionados con el Perú. La primera, homónima de nuestro país, ubicada en Nebraska, Estados Unidos, y la segunda, llamada Loreto, en Italia.

En una investigación realizada por Gisela Cánepa (2014), se explica que la polémica generada a partir del documental Peruanos en Nebraska (Perú-Nebraska) fue debatida -o entendida- en términos de veracidad y autenticidad 
de la representación que se hacía del Perú; sin embargo, al analizarlo desde ese ángulo nos conduce a un camino sin salida. Pensado más como una pieza publicitaria antes que como un documental, el producto audiovisual fue creado a partir de las estrategias del marketing. En otras palabras, su focalización no radica en el documento fidedigno del espacio geográfico, sino, muy por el contrario, se adscribe a patrones de eficacia, recordación, vivencias, conductas y lealtades. Por tanto, la publicidad no se detiene en hacer una cartografía detallada de la geografía, sino que se legitima en términos de verdad con respecto al mundo representado que construye a partir del imaginario.

Sin embargo, tengamos cuidado al afirmar lo anterior, pues se pensaría que las imágenes solamente se quedarían en el umbral de la presentación del mundo. Por el contrario, pensemos que esas imágenes creadas a partir de la narrativa publicitaria no son más que guiones para la acción. En ese mismo sentido, las imágenes ya no solo se legitiman en términos de verdad con respecto a un mundo representado, sino en términos de eficacia y eficiencia para producir eventos y experiencias.

No obstante, debemos ser críticos con la mirada de Cánepa, pues si bien para ella la publicidad -en especial la encargada del nation branding- es creadora de mitos nacionales, y por tanto de los deseos, nuestra postura es contraria. Para ello debemos entender a la publicidad dentro de la lógica de la creación a partir de la creencia. En ese sentido, debemos alejarnos de la lectura habitual que implica a la publicidad como creadora o autora de los deseos. Muy por el contrario, nuestra postura nos lleva a pensar la publicidad como una recolectora residual de los síntomas manifiestos en el espacio social. Es decir, en buena medida, como aquella que configura nuestro panorama urbano. No solo el exterior (el de la calle), sino también -y esto es, después de todo, lo decisivo- el interior de nuestros espacios domésticos. Así, como nos lo recuerda Landowski (2004), la publicidad traspasa largamente los límites de la esfera comercial hasta el punto de llegar-de manera implícita e indirectamente- al plano político. Por eso, cuando de aquí en adelante nos detengamos en el ámbito publicitario debemos pensar que no se juega en la arena del panorama urbano sino en el ámbito del paisaje imaginario.

La publicidad no pretende hablar de la realidad sino de una imagen deseable del objeto publicitario. En otras palabras, no se habla del objeto empírico o de la mercancía en juego, sino que se trata del más allá del deseo, 'lo otro' del deseo, que no radica en la cosa misma sino en la ausencia perpetua; pues no es 'lo' que se desea, sino la fantasía que existe 'alrededor' lo que lo hace inagotable. En síntesis, lo deseable no es nunca el objeto empírico sino su imagen $y$, por tanto, el campo de la fascinación visual.

Si seguimos la lógica del crear a partir de nuestro creer (creamos lo 
que creemos), ciertamente la creación de esta campaña ha quedado en manos de la creencia publicitaria. Ríspida situación, más aún en un país donde las agencias publicitarias suelen "contestar las críticas [racistas que se les imputan] diciendo que ellas deben de mirar por el interés de su cliente, siempre preocupado por aumentar sus ventas" (Portocarrero, 2013, p. 166).

Pero en este caso el cliente no es una tienda por departamentos o algún producto comestible. Es el Estado peruano, específicamente PromPerú, que ha tomado partido por 'alejarse' de la visión orientalista que muestra la típica postal del inca en la punta de una montaña o una ciudadela de barro (figura 3), para que -hoy en día- nos presente a un bufón que intercambia picarones con un sheriff en una ciudad norteamericana (figura 4).

En teoría, el nivel figurativo ha cambiado. Algunos optimistas afirman que se ha evolucionado. ¿Evolucionado? El término evolución hace referencia exclusiva a una nueva fase, donde la anterior ha quedado obsoleta, relegada. Nada más alejado de nuestra realidad. Si bien las figuras han cambiado, el nivel temático sigue erigiéndose bajo el mismo concepto orientalista de siempre: atemporal, irracional y fantástico.

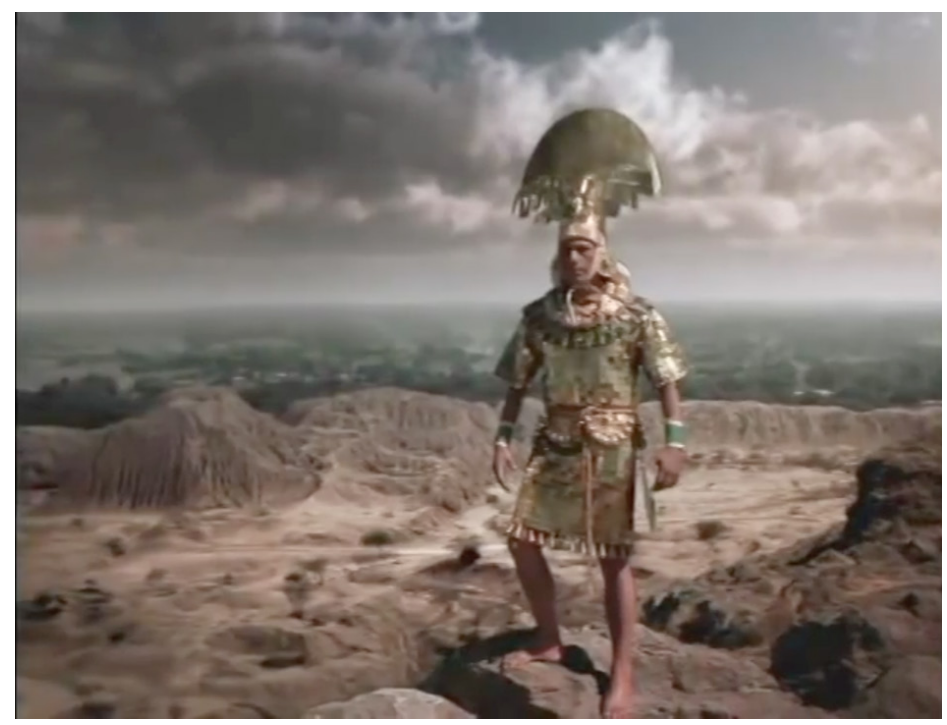

Figura 3. Inca en la montaña. Fragmento del spot publicitario Perú, vive la leyenda. Fotograma extraído del mencionado spot (septiembre de 2008). 


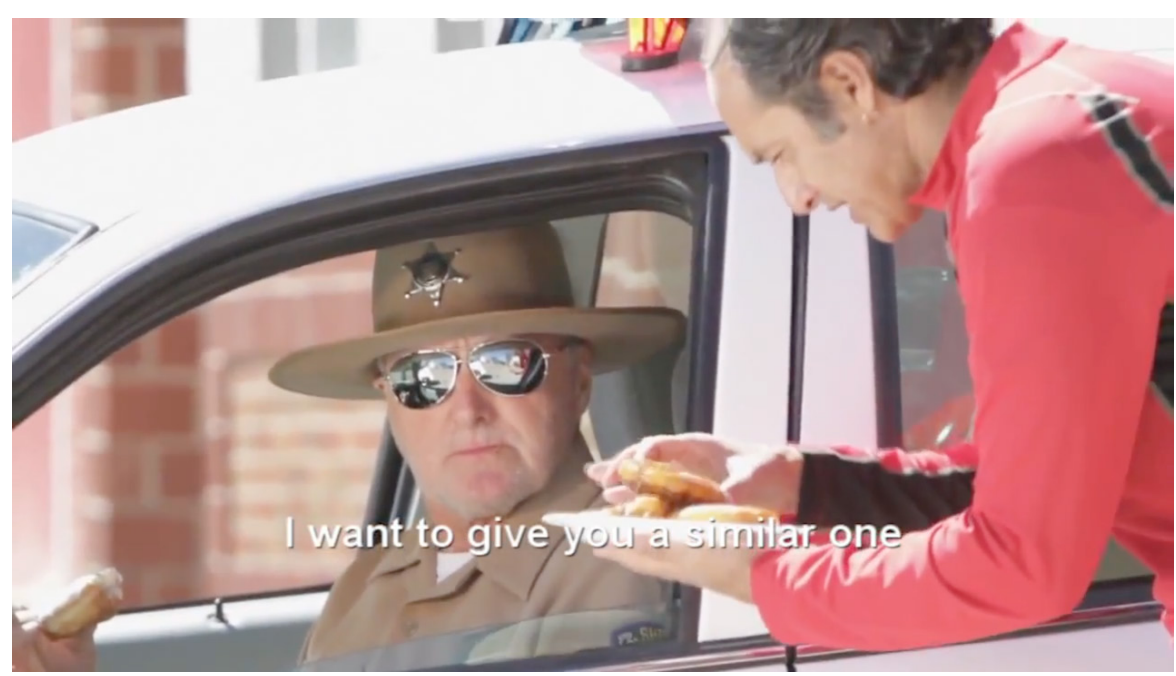

Figura 4. Cambio de orden. Fragmento del documental/spot publicitario Marca Perú. Fotograma extraído del mencionado documental (video oficial, 2011).

\section{Ser extranjeros dentro del propio territorio}

Por eso, la estrategia principal radica en la creación de una marca. Es decir, en la creación de algo mayor a la publicidad misma. Si partimos de que actualmente el desarrollo económico y social de una sociedad entraña imprescindiblemente una dimensión cultural, y que es entendido como un medio para acceder al desarrollo, entonces los aspectos culturales deben ocupar un lugar central en los planos y estrategias para lograr la expansión de la actividad.

De ese modo, cuando nace la Marca Perú en el imaginario social lo hace con una serie de directrices, que en principio parecen claras y fundantes: un proyecto independiente, reivindicador $y$, principalmente, dotador de iden- tidad. Todo esto en un Perú que crece económicamente, que se pone de moda en el mundo por sus personajes famosos, su comida, sus textiles, su moda, su minería, turismo y agroindustria. Sin embargo, sigue siendo un Perú con más de $20 \%$ de pobreza, con $25 \%$ de niños peruanos desnutridos, con $10 \mathrm{mi}$ llones de peruanos que no tienen agua potable, y con cada vez más conflictos sociales, como los de Conga o Bagua.

En el Perú, los indicadores de desarrollo social no aumentan a la velocidad que los indicadores económicos y, más bien, los conflictos sociales, la inseguridad ciudadana y la pésima relación política entre los ciudadanos y sus autoridades se agravan. La desconfianza parece ser el sentimiento generalizado que organiza nuestras relaciones sociales y la principal traba pa- 
ra la equidad y la inclusión. Los medios de comunicación, las redes sociales son plataformas que visibilizan, en muchas situaciones, esta relación perversa.

En este contexto problematizado, PromPerú -el órgano encargado de la promoción turística del Perú- optó por una nueva estrategia enunciativa. En el nivel narrativo se dejó de exhibir las ruinas arqueológicas para mostrar un pueblo de Estados Unidos, pero que al ser analíticos nos damos cuenta de que nos habla del estereotipo de los Andes. Sin embargo, este paso no solo debe de ser tomado como un cambio de estrategia, sino que debemos escudriñar en ello.

Si bien en las publicidades anteriores a la Marca Perú se remarca la isotopía de 'unificación', que podríamos resumir en el viejo apotegma arguediano 'todas las sangres', a partir de esta campaña observamos que la isotopía cambia de orden. De la 'unificación' pasamos a la 'personificación', del 'todos' al 'individuo', pues, al fin y al cabo, lo que nos recuerda la campaña -una y otra vez- es que la peruanidad no se obtiene, sino que se compra.

Por eso, como nos recuerda Bauman (2007), el Estado ha dejado de considerar ciudadanos para empezar a reclutar clientes. Es decir, la ciudadanía peruana ha quedado en manos de la 'compra de la peruanidad'. Para ello, primero, ha tenido que señalarlos como productos (el peruano producto) para después convertirlos en consumidores (de esa propia peruanidad).
En otras palabras, primero ser el producto Marca Perú para después ser 'la Marca' (Lury, 2004).

Así, Marca Perú se crea con el propósito de incentivar un 'goce consumista peruano' para aquellos que mueven la economía (los que van a Mistura [la gran feria gastronómica], los que compran el merchandising, los que creen que el país se está unificando y, por ello, sienten un orgullo de la comida o del turismo). Sin embargo, para aquellos otros que no pueden o que no quieren, se les configura como consumidores inválidos y defectuosos siempre anotados en la lista de los pasivos y, por tanto, vistos como intrusos o antiperuanos. En síntesis, su defecto radica en no poder comprar su peruanidad.

Bajo la lupa del discurso oficial, el país está inmerso en un proceso de reimaginación y rediseño de una comunidad nacional peruana, marcado por el espíritu celebratorio del desarrollo económico y de la inclusión, que traería por tanto la redistribución. De esta manera, desde el oficialismo se piensa que "la marca país representaría un discurso alternativo sobre la construcción de identidades colectivas, un discurso que es menos peligroso que el nacionalismo moderno" (Cánepa, 2014, p. 229).

Si consideramos que en esta publicidad se establece una identificación entre la condición de ciudadanía y la acreditación como embajador de la marca, surge una serie de preguntas que merecen ser discutidas: ¿qué tipo 
de régimen ciudadano se está instituyendo una vez que los derechos se encuentran al mismo tiempo vinculados a una lógica del mercado?, ¿cuáles son las complejidades y paradojas que se desprenden de esta identificación que se establece entre ser ciudadano peruano y ser un embajador de la Marca Perú?

En los tres spots, la adquisición de la peruanidad pasa por la domesticación de los sentidos que, en el mundo creado por la propia pieza publicitaria, dependen del consumo.

Es la vieja vuelta al maquillaje de la pobreza con 'asistencia', que dibuja al Perú en la postal añorada por la burguesía criolla que aún persiste. Es decir, un país que, al igual que la portada de la revista Industria Peruana mencionada en este escrito, propone que la única salida de la indianidad es a través del trabajo; y que hoy en día se puede leer en la clave que dice: el dinero blanquea. Por eso, la Marca Perú enuncia a un país donde para ser parte de su proyecto no solo se debe ser consumista, sino también hay que 'limpiarles la piel' a los andinos y convertirlos en indios blanquecinos de Perú-Nebraska, o en shipibos con una medialengua latina de Perú-Loreto.

De este modo, la asociación entre el color blanco de la piel, la prosperidad económica y la felicidad familiar se constituyen en el fundamento de la 'utopía del blanqueamiento', como proyecto transgeneracional de una mejora de la raza (Portocarrero, 2013, p. 168).
Estos spots proponen la fantasía de un país homogéneamente blanco, pues -de esa única forma- 'las diferencias desaparecerían'. Por eso se plantean tres spots que dejan ver en su devenir cómo se configura un simulacro de un país 'próspero': los Andes, en su concepción de una zona agreste, fría y sin mar, que se escenifica en Perú-Nebraska, y el estigma del jolgorio y predisposición del selvático para la fiesta en Perú-Loreto, o como dicen en el spot: "al sudor, calor y el color".

Todo esto se entiende con su contraparte, el spot Perú 2032, donde el gerente de una empresa, con un remarcado acento español, repasa su vida bajo una mirada constituida de una costa próspera, avanzada, futurista, que le lleva aproximadamente unos veinte o treinta años a los Andes y a la selva, que mira en las dos regiones anexas un tiempo que no ha transcurrido y que -por el contario- aún lo espera.

En síntesis, vemos cómo se enuncia desde la costa las configuraciones orientalistas -en el sentido de Edward Said-sobre lo que son los Andes y la selva. Es una costa que, al igual que las pinturas de castas, siempre ha visto con desprecio y horror a la mezcla y, por ello, su nexo está más cercano a España que al Perú; de allí que aún ahora existan concursos de la mejor paella o las mejores tapas en las playas de moda de la sociedad limeña.

Es decir, esta es una campaña donde se legitima el fantasma de una nación cercada por los Andes y la selva. 
A fin de no alienar de entrada a quienes ignoran la jerga psicoanalítica, nos apresuraremos a decir que para Lacan (1973) el fantasma es una forma inconsciente que ocluye lo real del deseo del sujeto; y para Slavoj Žižek (1997), es la pantalla que vela lo real de los antagonismos sociales. En ese sentido, la Marca Perú es el constructor de un fantasma, pues en su afán de sosegar la relación entre Estado-nación y, por tanto, Estado-nación-empresa, el 'ser peruano' se convierte en un ardid consumista. Por eso, este cerco se ha forjado por gente que vive en la premodernidad, donde no hay tiempo, lujo ni principalmente un goce capitalista, por ello estos spots configuran las directrices de un proyecto que pretende invisibilizar las diferencias y -por enésima vez- reactivar el viejo proyecto multiculturalista; un lugar donde el reconocimiento no hace más que proponer una falsa distribución superficial a los grupos existentes, pero donde siempre prevalece un centro y su periferia (Fraser, 2000). De ese modo, cada vez vemos cómo lo peruano -o lo que se pueda entender de él- deja de serlo para convertirse en 'aperuanados'; y así constituir una copia sin original, un proyecto del Perú sin peruanos (Baudrillard, 1970).

Mejorar la raza, importar nuevos andinos, parece ser el tenor con el que se enuncian estas publicidades. $\mathrm{Y}$ es que junto con la formulación de nación, su advenimiento como sistema de significación cultural, como la representación de la vida social más que como una disciplina de organización, nos coloca en situación in media res; es decir, en un discurso ambivalente, poroso, donde la enunciación no solo se construye desde la hegemonía sino también desde su negociación.

Por eso, cuando tratamos de hacer una genealogía de las naciones, al igual que las narraciones, se pierde en los mitos del tiempo, y recién alcanza su horizonte en el 'ojo de la mente' (Bhabha, 2010, p. 11). Justamente, la Marca Perú se ha afianzado como un sincretismo, como una imagen, como un símbolo nacionalista que debemos desligar de las ideologías políticas conscientes, para así adherirla a los grandes sistemas culturales que la precedieron, de donde surgió -paradójicamente- por oposición (Anderson, 1983, pp. 29-30).

Este trabajo no está, pues, en función de recordar lo dicho por la voz oficial, sino de encontrar los resabios coloniales manifiestos en estos spots. Lo blanco se opone a lo indio, pero claro está bajo una lógica de contrariedad y, por tanto, de dependencia. Y es que el espacio enunciativo de lo blanco alberga lo que Freud (2012) denominó como Heimlich, es decir, lo familiar o lo reconocido. Sin embargo, en espacio de dependencia, es decir de que no existe el uno sin el otro, pues se erige como lo contrario (si uno es letrado, el otro es iletrado; si uno es nativo, el otro es forastero). Justamente lo 'indio' -escenificado en los pobladores de Nebraska y Loreto- es propuesto en la campaña como lo forastero, aquel que 
vive en un lugar alejado, agreste, hostil, laberíntico, inaccesible y, por tanto, carente de comodidades, principalmente de goce.

De ahí que lo indio es Unheimlich, la conversión de lo familiar en extraño, incluso en lo siniestro. De ese modo, /familiar/ y /extraño/ conviven en relación de la fantasía sobre aquello que no sea el espacio hegemónico de enunciación.

Sin embargo, debemos darnos cuenta de que la construcción de la nación no solo está configurada a partir de oposiciones contrarias, sino también de contradicciones. Es decir, categorías que parten de la negación y, por tanto, se mantienen en el espacio irreconciliable de la convivencia del término. Lo mestizo (como la negación de lo blanco) y lo criollo (como negación de lo indio), se abren paso para convertir nuestra nación en ese lugar poroso del que Bhabha hace mención.

Démonos cuenta de que -en la tónica de estos spots- lo mestizo se configura a partir de la negación de lo blanco (por eso el poblador es un proyecto 'ci-

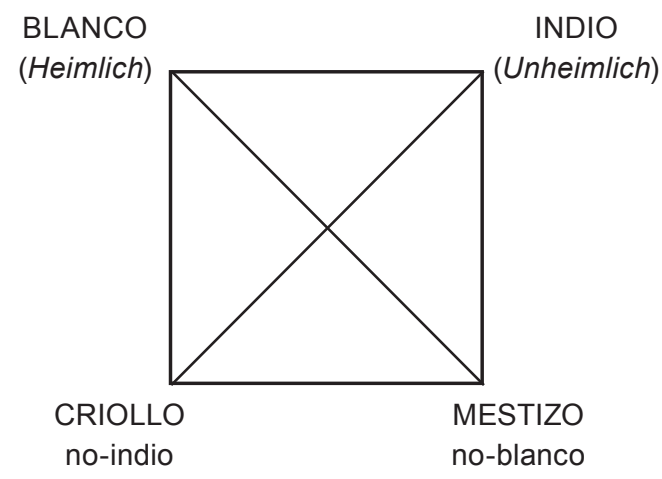

vilizatorio fallido', que aparece descuidado, incluso como abandonado a su suerte), más cercano a la pobreza que a la riqueza, más cercano al estereotipo del campesino y, por tanto, del andino.

De ese modo, lo mestizo se erige como aquello que es la negación de lo blanco, pues a pesar de la industrialización, el proyecto de mejorar la raza no funcionó, lo mestizo está en aserción a lo andino. Del mismo modo, lo criollo construye su perspectiva enunciativa a partir de la fricción irreconciliable con lo indio, en abducción con lo blanco (pero sin llegar a serlo).

Así, estas son directrices que conforman el imaginario de nuestra nación. Es decir, un espacio lleno de contrariedades y contradicciones,

como una forma de elaboración cultural, un medio de narración ambivalente que mantiene a la cultura en su posición más productiva, como una fuerza para 'subordinar, fracturar, difundir o reproducir, en igual medida que [para] producir, crear, imponer o guiar'. (Said, 2004, p. 232)

En síntesis, apelar a la nación no es nada más que apelar a una imagen, a una metáfora asociada con algo no definido. Debido a ello, ante este vacío, la imagen que se presenta en los spots de la Marca Perú es 'performativa', porque incita a la acción del público. Por eso, de un acto 'tan inocente' como ir a Mistura (la gran feria gastronómica anual que 'une' a los restaurantes de todo el país) o de entrar en el juego de la maravilla del país, se empiezan 
a invisibilizar o, como llamaremos de ahora en adelante, a cegar -no en función de una oscura patraña que obnubila los conflictos- las creencias en torno a las diferencias que existen en el país. Es así como Alan García (2007), ex presidente del Perú, hizo referencia en "El síndrome del perro del hortelano", que los habitantes de la selva son gente mezquina que, en vez de dejar trabajar al Estado, se interponen en el camino del 'desarrollo'. Esto resume claramente la apuesta de la 'Marca Perú', una suerte de aplicación de la frase anglosajona: my way or the highway (por las buenas o por las malas).

Por lo tanto, la legitimidad de los recursos de peruanidad responden a criterios de competitividad. Mientras que aquellos repertorios que podrían ser representativos, pero no garantizan un buen desempeño en el mercado, es decir, que tienen una performance débil, quedan fuera.

\section{Desenlace abierto}

Este es el tiempo de una integración aparente, pero solo para aquellos que tengan cómo sustentar su peruanidad, con dinero en el banco, efectivo o cualquier otro elemento. Finalmente, la piedra en el zapato del Estado -las zonas menos favorecidas por el Estado- terminarán por ser repudiadas hasta instaurar en la médula del discurso un panorama naturalista $\mathrm{y}$ 'legítimo', donde la privatización de una playa, la negación de usar los baños a las trabajadoras del hogar en vez de ser denunciadas serán avaladas. Es decir, este discurso será invisibilizado hasta llegar al punto de 'decir/pensar' sin mayor consideración que: "Por aquellos que 'invaden la ciudad' para gozar con mi trabajo; el goce de ser peruano se ve despoblado". Y es que, aunque esto es una verdad no solo de este tiempo, se convertirá en la verdad hegemónica, natural, al mejor estilo de Foucault (1966) o Gramsci (1988).

Nuevamente, en clave de Bauman (2007), los objetos de la Marca Perú son los ciudadanos que saben cómo ser peruanos para después poder ejercer sus derechos. Pues la norma implica que aquellos que 'no saben ser peruanos' no tienen derechos, territorio ni nación. Amparados en la 'bonanza' económica, el Perú es en este momento un país donde la igualdad, la libertad y la fraternidad se coalicionan con el Estado, el mercado y la nación (Karatani, 2005).

Es decir, el Estado procura la igualdad de los habitantes (los que sí son peruanos y saben cómo serlo, ellos sí tienen derecho a ser peruanos), la fraternidad de un pueblo 'unido' en la multiculturalidad (aunque los mismos funcionarios del Estado no sepan lo que significa) y la libertad, que pasa exclusivamente por el mercado.

De allí que Bauman (2007) sostenga que este es el tiempo del fetichismo de la subjetividad. Siguiendo esta lógica, si el Estado es el que regula la 'igualdad', y la 'fraternidad' pasa por la 'nación', entonces el único garante 


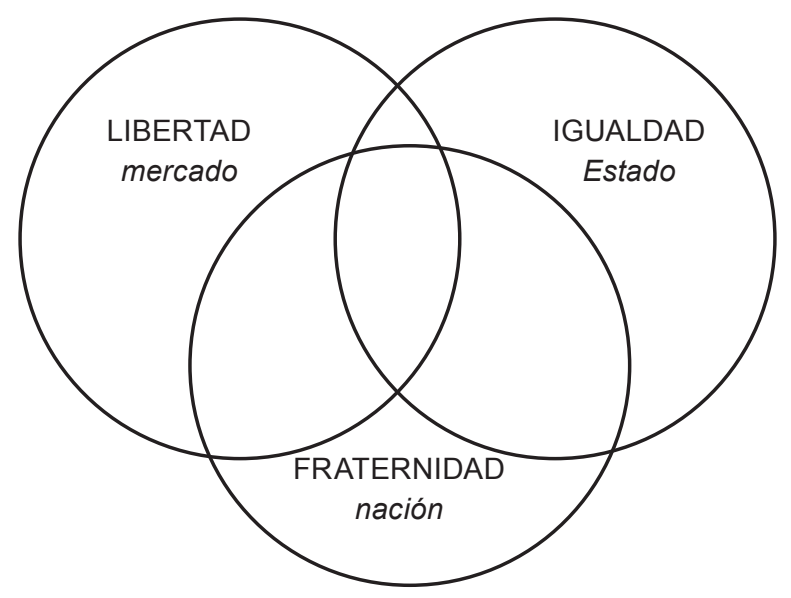

de la 'libertad' es el 'mercado'. Por eso, reconozcamos que los mercados están necesariamente insertos en matrices políticas y culturales muy complejas, que dan a los actos de consumo su resonancia específica y trascendencia. Demos cuenta de cómo el resultado de esta tendencia ha ensanchado la brecha entre el 'poder de actuar', que ahora se ha deslizado hacia el mercado, $y$ la 'política', que -si bien sigue siendo del dominio del Estado- es despojada de su libertad de maniobra y su poder para fijar reglas y arbitrar el juego. Como anota Víctor Vich (2007), si bien todavía en apariencia dictan y ejecutan los veredictos de exclusión y desalojo, los organismos del Estado ya no son dueños de decidir los criterios de esa 'política de exclusión' o los principios de su aplicación.

No todos los peruanos tienen acceso al tipo de consumo propuesto por la campaña, ni el gusto de todos los peruanos está moldeado para aquel re- pertorio representativo. En tal sentido, resulta problemático que sea el consumo precisamente lo que opera como indicador de los derechos ciudadanos.

Así, la identidad nacional no se concibe en términos de un origen y una historia comunes, sino en términos de valor, de competitividad. En ese sentido, la marca tampoco se legitima en términos de autenticidad, sino de acreditación.

Bien lo decía Sócrates, pues "si una vida no es examinada, no debe vivir$\mathrm{se}^{\prime \prime}$. Lo mismo podemos decir en torno a nuestro objeto de estudio: una marca que no es examinada no debe marcarse (en el imaginario de los peruanos).

\section{Referencias}

Agamben, G. (2005). Estado de excepción. Buenos Aires: Adriana Hidalgo Editora.

Anderson, B. (1983). Imagined communities. Reflections on the origins 
and spread of nationalism. Londres/ Nueva York: Verso.

Anholt, S. (2007). Competitive identity. The new brand management for nations, cities, and regions. Nueva York: Palagrave McMilan.

Arellano, R. (2007). Bueno, bonito, barato I. Aprendiendo marketing con historias de la vida cotidiana. Lima: Planeta/Arellano Marketing.

Arellano, R. (2010). Al medio hay sitio. El crecimiento social según los estilos de vida. Lima: Planeta/Arellano Marketing.

Arellano, R. (2012). Somos más que siesta y fiesta: doce mitos y verdades sobre América Latina. Lima: Planeta.

Arellano, R. (2013). Marketing para vivir mejor. Lima: Gestión 2000.

Arellano, R., y Burgos, D. (2010). Ciudad de los Reyes, de los Chávez, de los Quispe. Lima: Planeta/Arellano Marketing.

Baudrillard, J. (1970). La société de consommation. Ses mythes, ses structures. París: Éditions Denoël.

Bauman, Z. (2007). Consuming life. Cambridge: Polity Press.

Bhabha, H. (2010). Nación y narración. Entre la ilusión de una identidad y las diferencias. Buenos Aires: Siglo XXI/Clacso.

Cánepa, G. (2014). Peruanos en Nebraska: una propuesta de lectura crítica del spot publicitario de Marca Perú. En A. Sánchez León, Sensibilidad de frontera. Comunicación y voces populares (pp. 207-235). Lima: Pontificia Universidad Católica del Perú, Fondo Editorial.
Ccopa, P. P. (2014). La institución sensorial de la idea de nación. La función de la comida. En G. Portocarrero, Perspectivas sobre el nacionalismo (pp. 99-113). Lima: Red para el Desarrollo de las Ciencias Sociales.

Chatterjee, P. (2008). La nación en el tiempo heterogéneo y otros estudios subalternos. Buenos Aires: Clacso/Siglo XXI.

Drinot, P. (2011). The allure of labor. Workers, race and the making of the Peruvian State. Durham: Duke University Press.

Foucault, M. (1966). Les mots et les choses. Una archéologie des sciences humaines. París: Gallimard.

Foucault, M. (1999). Estética, ética y hermenéutica. Obras esenciales (Vol. III). Barcelona: Paidós.

Foucault, M. (2012). Nacimiento de la biopolítica: curso en el College de France (1978-1979). Buenos Aires: Fondo de Cultura Económica.

Foucault, M. (2014 [1976]). Vigilar y castigar. Nacimiento de la prisión. México, D. F.: Siglo XXI.

Fraser, N. (2000). Rethinking recognition. New Left Review, 3. Recuperado de http://newleftreview.org/II/3/nancy-fraser-rethinking-recognition

Freud, S. (2012). Lo siniestro. En S. Freud, Obras completas (Vol. III, pp. 2483-2505). Buenos Aires/Madrid: Siglo XXI/ Biblioteca Nueva.

Fuller, N. (2009). Turismo y cultura. Entre el entusiasmo y el recelo. Lima: Pontificia Universidad Católica del Perú, Fondo Editorial. 
García Pérez, A. (28 de octubre de 2007). El síndrome del perro del hortelano. El Comercio. Recuperado de http://www.justiciaviva.org.pe/ userfiles/26539211-Alan-Garcia-Perez-y-el-perro-del-hortelano.pdf

Gramsci, A. (1988). Antología. México, D. F.: Siglo XXI.

Karatani, K. (2005). Transcritique: On Kant and Marx. Massachusetts, Estados Unidos: MIT Press.

Lacan, J. (1973). Le Séminaire, livre XI. Les quatre concepts fondamentaux de la psychanalyse. París: Seuil.

Landowski, E. (2004). Passions sans nom. Essais de socio-sémiotique III. París: PUF.

López Maguiña, S. (2007). Inca Kola: la esencia del Perú. En S. López Maguiña, G. Portocarrero, R. Silva Santisteban, J. Ubilluz, y V. Vich, Industrias culturales. Máquinas de deseos en el mundo contemporáneo (pp. 345-365). Lima: Red para el Desarrollo de las Ciencias Sociales.

Lury, C. (2004). Brands. The logos of the global economy. Londres/Nueva York: Routledge.

Méndez, C. (1995). Incas sí, indios no. Apuntes sobre el estudio del nacionalismo criollo. Lima: Instituto de Estudios Peruanos.

Patiño-Patroni, A. (2013). Entre viejos patrones y nuevos gerentes: remanentes simbólicos y nuevos regímenes de verdad. En G. Portocarrero, Sombras coloniales en el Perú de hoy (pp. 167-185). Lima: Red para el Desarrollo de las Ciencias Sociales.

Parret, H. (2008). Epifanías de la presencia. Ensayos semio-estéticos. Lima: Universidad de Lima, Fondo Editorial.

Portocarrero, G. (2010). Los fantasmas del patrón y del siervo como desestabilizadores de la autoridad legal en la sociedad peruana. En G. Portocarrero, J. Ubilluz, y V. Vich, Cultura política en el Perú. Tradición autoritaria y democratización anómica (pp. 13-29). Lima: Red para el Desarrollo de las Ciencias Sociales.

Portocarrero, G. (2013). La utopía del blanqueamiento y la lucha por el mestizaje. En A. Grimson y K. Bidaseca, Hegemonía cultural y políticas de la diferencia (pp. 165-200). Buenos Aires: Clacso.

Portocarrero, G. (2014). Perspectivas sobre el nacionalismo. Lima: Red para el Desarrollo de las Ciencias Sociales.

Puig, T. (2008). Marca ciudad. Cómo rediseñarla creativamente para afrontar diferencia y vida emergente. Barcelona como estilo. Barcelona/Buenos Aires: Editorial Personal.

Said, E. (2004). El mundo, el texto y el crítico. Buenos Aires: Debate.

Seminario, B., Sanborn, C., y Alva, N. (2013). Cuando despertemos en el 2062. Visiones del Perú en 50 años. Lima: Universidad del Pacífico.

Ulfe, M. E. (2011). ¡Sal de la rutina! Sobre cómo se imagina y se construye la imagen del Perú. En G. 
Cánepa, Imaginación visual y cultura en el Perú (pp. 327-340). Lima: Pontificia Universidad Católica del Perú, Fondo Editorial.

Vich, V. (2007). Magical, mystical: El Royal Tour de Alejand ro Toledo. En S. López Maguiña, G. Portocarrero,
R. Silva Santisteban, J. Ubilluz y V. Vich, Industrias culturales. Máquinas de deseo en el mundo contemporáneo (pp. 313-325). Lima: Red para el Desarrollo de las Ciencias Sociales. Žižek, S. (1997). The plague of Fantasies. Londres: Verso. 